ACTA THERIOLOGICA

Vol. 22, 34: 509-520, 1977

\title{
Two Ageing Methods for Muskrats: Live or Dead Animals
}

\author{
Eric Le BOULENGÉ
}

Le Boulengé E., 1977: Two ageing methods for muskrats: live or dead animals. Acta theriol., 22, 34: 509-520 [With 4 Tables \& 5 Figs.].

A new method is presented for ageing living muskrats, Ondatra zibethicus (Linnaeus, 1766). It consists of fitting a second-order polynomial to a set of measurements of tail length, taken at various ages of an unknown-age animal. The birth date is estimated as the time at which tail length equals the mean tail length for muskrats at birth. Tested with known-age muskrats, this method yields unbiased estimates, even for animals two months old when first measured. It is moreover based on sounder assumptions than the "classical age estimation by reference to a growth curve calibrated on known-age animals. A reference growth curve of the crystalline weight is next given; $95 \%$ confidence interval to age amounts to approximately $11 \%$ of the estimated age. The crystalline lens growth in a group of confined muskrats was slower than for animals raised in natural conditions.

[Labo. Ecol. theor. et Biom., U.C.L., Place Croix du Sud 5, 1348 Louvain, Belgium].

\section{INTRODUCTION}

To describe any age-specific characteristic of an animal, knowledge of its age is necessary. Animal population studies may deal with living or with dead individuals. Few parameters indicative of age may practically be measured on living animals, but measurements may be repeated at various ages of each individual. On dead animals on the contrary, many parameters may be measured, at only one particular age. The kinds of information thus differ and distinct analysis techniques should be used in these two situations.

The techniques and parameters used for ageing rodents were reviewed by $\mathrm{Pucek} \&$ Lowe (1975); methods adapted to the age estimation in muskrats were considered by $\mathrm{Ruprecht}$ (1974). The general principle is to compare a measure on the unknown-age individual, to a growth curve calibrated by measuring known-age animals. The optimal parameter thus is the one with minimal inter-individual variability. Such calibration curves of weight, tail length and body length are presented by Errington (1939), Dorney \& Rush (1953) and Erickson (1963), as means to estimate the age of living muskrats. The growth rate of these characteristics varies as a function 
of various factors (i.e. genetic, climatic,...); whence the proposed reference curves lack generality. With dead animals, it is more probable that a parameter will be found, whose growth is nearly independent from external sources af variation. Among the parameters approaching this ideal, the weight of the crystalline lens of the eye seems a wellsuited age indicator for many rodent species (L ord, 1969; A skaner \& Hansson, 1967; Fisher \& Perry, 1970; Andrzejewska, 1971; Vincent \& Quéré, 1972); moreover, the measurement of this characteristic is easier to perform and to standardize than for most osteometric or biochemical parameters (S a th e r, 1954; $\mathrm{K} u$ precht, 1974; D a p s on et al., 1968). Accordingly, the crystalline weight was chosen as age indicator for dead muskrats in this study.

\section{AGEING LIVE ANIMALS BY EXTRAPOLATION OF THEIR GROWTH CURVE}

\subsection{Description of the Method}

This method takes advantage of repeated measurements of a growing characteristic on an unknown-age animal, to estimate its age. The method will be described using tail length as age indicator, as this seems well suited for muskrats (Dorney \& Rush, 1953). Besides the set of measurements from the unknown-age animal, two more informations are needed: the expected tail length at birth and a function relating tail length to age. The mean tail length at birth was obtained from wild and captive new-born muskrats, as $2.74 \mathrm{cms}$. $( \pm 0.15 \mathrm{cms} ., 95 \%$ confidence interval). This is in agreement with the data presented by Errington (1939), Dorney \& Rush (1953) and Erikson (1963). As a function describing tail growth, a second-order polynomial was found adequate for muskrats up to six months in age.

Thus, from as set of measurements of tail length at different times $\left(t_{1}, t_{2}, \ldots, t_{\dot{n}}\right)$ on an unknown-age individual, we estimate the coefficients of the equation:

$$
\widehat{Y}=b_{0}+b_{1} t+b_{2} t^{2}
$$

where $t=$ time (days) from an arbitrary origin

$\mathrm{Y}=$ tail length $(\mathrm{cms}$.

$b_{i}=$ coefficients.

Let $t_{\theta}$ be the position of the birth date on the time-axis; then, its estimation, $\hat{t}_{0}$, is the time value for $Y=2.74 \mathrm{cms}$. (Fig. 1). The common least-squares procedure yields estimates of the coefficients $b_{i}$ and of the various variance and covariance components. Assuming homogeneity of the residuals, interval confidence of $t$ for given $Y$, may be obtained 
by application of an optimization method (Le Boulengé \& Feyt$\mathrm{m}$ a $\mathrm{ns}$, in prep.).

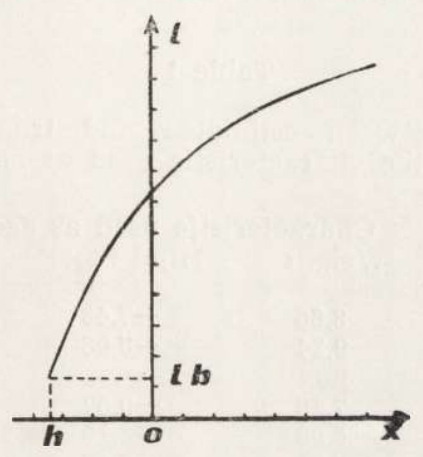

Fig. 1. Illustration of the growth-curve extrapolation method of age estimation. $l$ : length (or value of the characteristic used as age-indicator).

$l b$ : length at birth.

$x$ : time-axis, starting from an arbitrary date 0 , i.e. that of first observation.

$h$ : birthdate estimated by extrapolation of the growth-curve (value of the abscissae at which predicted tail length is $l b$ ).

\subsection{Results}

2.2.1. Choice of the Age-indicator

Three characteristics easily measured on living animals in the field, were initially retained as potential age-indicators: body weight, tail length and hind-foot length. The deviations between true birthdate and the estimations yielded by the extrapolation method, were compared for these three characteristics, using the data of 13 known-age muskrats (Table 1). The hypothesis, that mean deviation is nil, is accepted at the 0.05 significance level, only for tail length data. The proportion of variance unexplained by the regression is smallest for tail length, generally below $1 \%$, while it ranges from 2 to $8 \%$ for the other two characteristics. Tail length was thus chosen as the most adequate of these age-indicators.

\subsubsection{Variability of Age Estimation According to Age at First Measurement}

The exactness of the age estimations derived by the extrapolation method may be influenced by the age at which the measurements start on the unknown-age individual. This influence was studied using the data from 11 known-age muskrats. The age estimation method was applied to each individual, successively using its measurements taken from birth on, next only those taken after the age of 25 days, finally 
those taken after age 50 days. The deviation between true and estimated birthdate was calculated for each individual in these three situations (Table 2). The mean deviation differs according to the age at which

Table 1

Deviations between estimated and true birthdates according to the characteristic used as age indicator.

\begin{tabular}{|c|c|c|c|}
\hline \multirow{2}{*}{$\begin{array}{c}\text { Animal } \\
\text { No. }\end{array}$} & \multicolumn{3}{|c|}{ Characteristic used as age indicator } \\
\hline & Weight & Hind foot & Tail length \\
\hline 1 & 8.66 & -7.43 & 0.37 \\
\hline 2 & 9.34 & -6.96 & 1.54 \\
\hline 3 & 1.82 & -4.87 & -1.82 \\
\hline 4 & 7.56 & -9.57 & -2.95 \\
\hline 5 & 6.06 & -3.10 & -0.07 \\
\hline 6 & 6.91 & -3.67 & -0.88 \\
\hline 7 & 5.64 & -2.21 & 0.74 \\
\hline 8 & 2.27 & -3.69 & 0.92 \\
\hline & 3.17 & -4.11 & 1.31 \\
\hline 10 & -1.84 & -5.99 & -11.16 \\
\hline 11 & -5.65 & -4.89 & -10.39 \\
\hline
\end{tabular}

Difference between characteristics: $P<0.0001$

Difference between individuals: $0.05<P<0.025$ Legend: Deviation = estimated minus true birthdate (days), $P=$ probably level of the significance of the factor (analysis of variance, $F$ test).

Table 2

Deviations between estimated and true birthdates according to age at first measurement.

\begin{tabular}{crrr}
\hline \multirow{2}{*}{$\begin{array}{c}\text { Animal } \\
\text { No. }\end{array}$} & \multicolumn{3}{c}{ Age at first measurement } \\
& 0 Day & 25 Days & 50 Days \\
\hline 1 & 0.37 & 0.04 & 2.30 \\
$\mathbf{2}$ & 1.54 & 1.48 & -3.99 \\
3 & -1.82 & -16.21 & 8.17 \\
4 & -2.95 & -14.04 & -0.98 \\
5 & -0.07 & -4.67 & 0.70 \\
6 & -0.88 & -6.50 & -1.03 \\
7 & 0.74 & -5.29 & 5.89 \\
8 & 0.92 & -3.18 & -0.43 \\
9 & 1.31 & 0.68 & -16.28 \\
10 & -11.16 & -19.29 & -14.93 \\
11 & -10.39 & -19.50 & -10.90 \\
\hline
\end{tabular}

Difference between ages: $0.05<P<0.025$

Difference between individuals: $0.025<P<0.01$

Legend: as in Table 1.

the observations start, being significantly different from 0 in the case the measurements start at the age of 25 days. The bias in age estimation observed when observations start at this age may indicate a modification 
in tail growth at the age of 25 days. Muskrats start swimming actively at this age. The above mentioned bias was not observed in two individuals reared without a place to swim (No. 1 and 2 of Table 2).

Precision of the age estimations is quite variable between the individuals, probably because of temporary irregularities in the tail growth. A substantial gain of precision may be attained by joining into one sample the data from various same-age individuals (e.g. a litter). The extrapolation age estimation method was applied to four known-age litters of muskrats (Fig. 2); here the maximum observed deviation

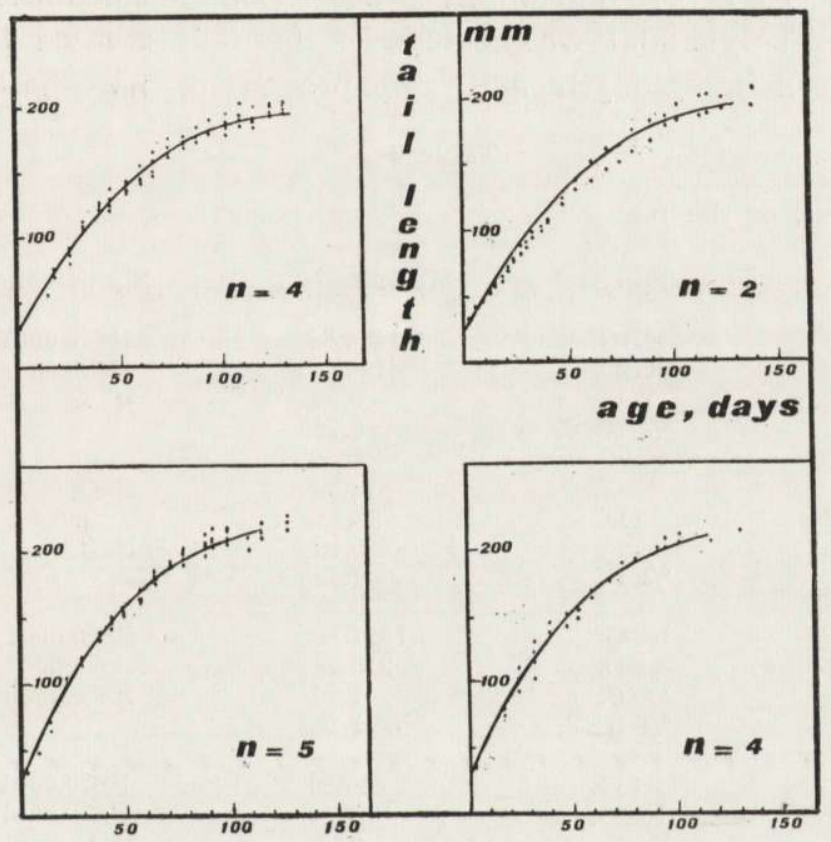

Fig. 2. Observed tail growth data and fitted polynomials for four litters of muskrats born in captivity (n: number of animals in each litter).

between estimated and true birthdate did not exceed 8.6 days when measurements started at the age of 25 days, and 3.8 days when they started at the age of 50 days.

2.2.3. Study of the Assumptions Underlying the "Extrapolation" and the "Classical" Methods

To compare the validity of the extrapolation method with that of the "classical " growth-calibration method of age estimation, the respective underlying hypotheses are examined. The growth-calibration method relies on the following assumptions: 
(1) The type of function postulated to describe tail growth is valid for any individual of the population; (2) All animals of the population have a same tail length at birth; (3) The coefficients of tail growth are of identical value for all the animals of the population.

On the other hand, the extrapolation of growth curve method assumes hypotheses (1) and (2), but is independent from hypothesis (3), as the coefficients of tail growth are estimated from the data of the unknownage individual itself. The validity of these hypotheses was tested using the growth data of four known-age litters of muskrats, measured weekly from birth on. To investigate on hypothesis (1), the goodness of fit of a second order polynomial was tested. In the four studied litters, the relation between tail length and age proved to be nonlinear, but

Table 3

Analysis of the regression of tail length as a function of age.

\begin{tabular}{cccc}
\hline Litter & Source & Mean square & Significance \\
\hline 1. & REG. & 1056.88 & $\mathrm{P}<0.0001$ \\
& RED. & 193.89 & $\mathrm{P}<0.0001$ \\
& DEP. & 0.06 & $\mathrm{~N} . \mathrm{S}$. \\
\hline \% RES. & 0.765 & \\
\hline 2. & REG. & 570.08 & $\mathrm{P}<0.0001$ \\
& RED. & 96.96 & $\mathrm{P}<0.0001$ \\
DEP. & 0.48 & $\mathrm{~N} . \mathrm{S}$. \\
\% RES. & 1.393 & $\mathrm{P}<0.0001$ \\
3. & REG. & 1021.38 & $\mathrm{P}<0.0001$ \\
& RED. & 215.58 & $\mathrm{P}<0.0005$ \\
& DEP. & 1.00 & \\
\hline \% RES. & 1.242 & $\mathrm{P}<0.0001$ \\
& REG. & 640.89 & $\mathrm{P}<0.0001$ \\
& RED. & 87.95 & $\mathrm{~N} . \mathrm{S}$. \\
\hline
\end{tabular}

Legend:

Litter: joint data, from birthdate on, of all members of a litter.

REG.: part of the variance in tail lengths, accounted for by the regression.

RED.: reduction in the residual variance obtained by inclusion of a second-order term, after a linear regression is fitted to the data.

DEP.: variance due to the departures from (lack of fit of) the second-order polynomial.

$\%$ RES.: percentage of the variance in tail lengths, which is not accounted for by the regression.

departures from the second-order polynomial was non significant in three of them (Table 3). In the fourth, departure from the second-order model is significant, although from graphical inspection (litter 3, Fig. 2) one would expect a good fit. The significant effect here may be due 
to an increase with age, of the variability in tail lengths (see $\mathrm{Sn}$ edecor \& Cochran, 1969, p. 457). Thus it seems that, at least for these four litters, tail growth could safely be described using a secondorder polynomial, till 130 to 170 days of age. Data from a natural population of muskrats, to be published elsewhere, support this hypothesis in the case of wild-living muskrats.

No sufficient data were available to investigate on hypothesis (2); nevertheless, departures from this assumption probably will induce a minor bias in age estimation, since they occur at the time of most rapid tail growth.

Finally to test hypothesis (3), tail growth from 0 to 50 days of age was described by linear regressions for the 4 litters of muskrats. The slopes and elevations of the regression lines show significant betweenlitter differences (analysis of covariance, $P<0.0005$ in both parameters). This demonstrates that hypothesis ( 3 ) has to be rejected, and invalidates age estimation methods relying on it.

\subsection{Conclusion}

The extrapolation of growth-curve method offers a means to estimate the age of living animals, taking advantage of the repeated measurements on the unknown-age individuals. This method is superior to the "classical " reference to a calibrated growth curve, as it does not rely on the unrealistic hypothesis of a same growth rate for all the individuals in the population.

\section{GROWTH CURVE OF THE LENS FOR AGEING DEAD MUSKRATS}

\subsection{Material and Methods}

Twenty-three known-age muskrats (9 from nature, 14 from captivity) were sacrificed at various ages, from birth to 700 days. The lenses were dissected after fixing the eyes for one year in a $10 \%$ formalin solution (A skaner \& Hansson, 1967; Fisher \& Perry, 1970). Once dissected, the lenses were dried during 8 days at $80^{\circ} \mathrm{C}$; in fact, no more significant change occurs in their weight after the fifth day of dessiccation. A further two days at $110^{\circ} \mathrm{C}$ brought no significant modification in the lens weights, so dessiccation at $80^{\circ} \mathrm{C}$ may be considered as complete as at $110^{\circ} \mathrm{C}$. All weighing was performed with a microelectrobalance Beckmann ( $0.01 \mathrm{mgr}$. precision); mean weight of the two lenses was used to characterize each individual. The relation between lens weight and age (Fig. 3) will be described separately for two groups of muskrats, the first grown in natural or semi-natural conditions, and the second, in confined conditions (small cages and no adequate swimming place). 


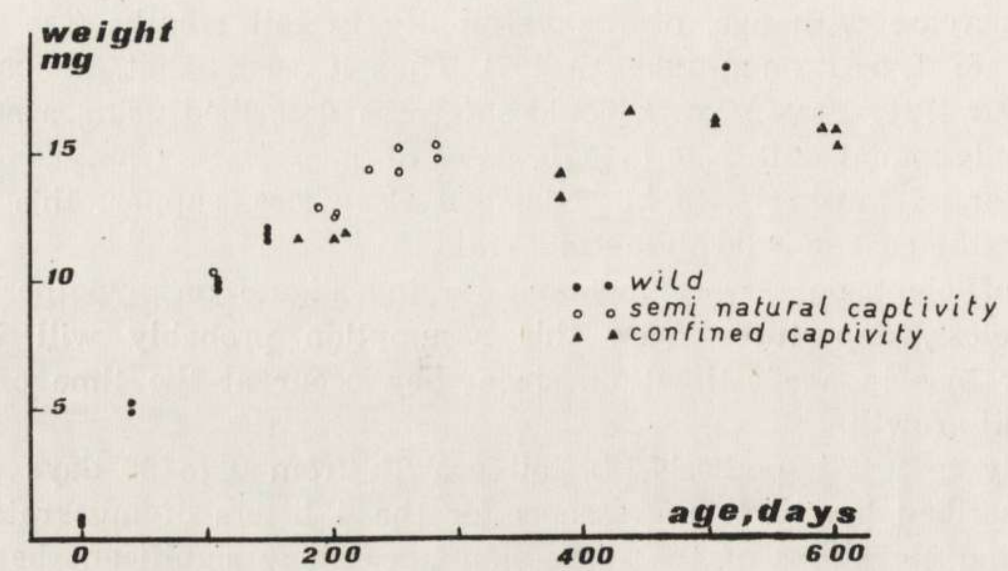

Fig. 3. Observed lens weight as a function of age for three groups of muskrats: wild, captive in semi-natural conditions and captive in confined conditions.

\subsection{Results}

The analysis of linear regression of the lens weight as a function of the natural logarithm of age is presented in Table 4 for the group of muskrats reared in natural conditions. To overcome the difficulty

Table 4

Regression of the lens weight as a function of age.

\section{A. Regression equation.}

$$
\begin{gathered}
\hat{Y}=-19.583248+6.032891 \ln (X) \\
\left.s^{2}=0.098 \text { (12 d.f. }\right)
\end{gathered}
$$

B. Age estimation.

Point estimation:

$$
\hat{X}=\exp \left(\frac{Y+19.583248}{6.032891}\right)
$$

Fiducial limits for age, at the $95 \%$ probability level (see Willi a m s, 1959, p. 96):

$$
\ln (X)=\ln (\hat{X})-0.00673 \pm 0.16514 \sqrt{1.04207+\frac{(\ln (\hat{X})-4.96388)^{2}}{20.07699}}
$$

Legend:

$Y$ : lens weight (mgrs.) rithm of $X$

$\exp (X): e^{x}$

$s^{2}$ : residual variance; d.f.: degrees of freedom. 
of $\ln (0)=-\infty$, age was counted from the day of conception, assumed 27 days previous to birth (Ols e $n, 1959)$. The regression line, observed data and $95 \%$ tolerance interval for age, are presented in Fig. 4.

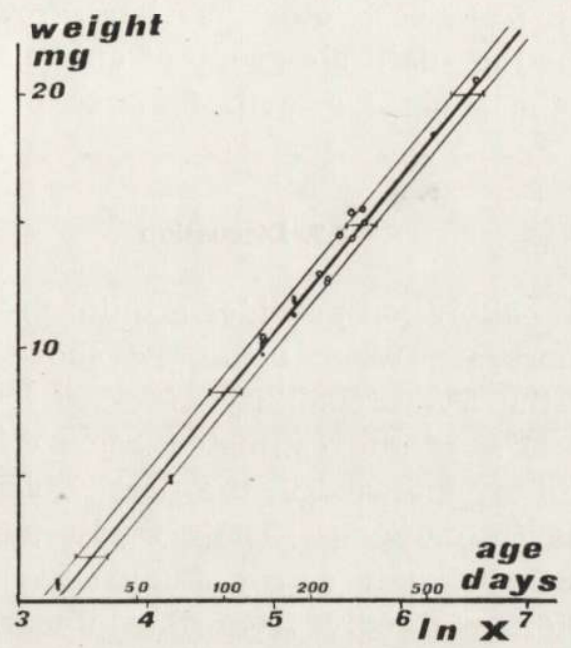

Fig. 4. Observed lens weights, linear regression of lens weight as a function of the natural logarithm of age (dated from conception) and $95 \%$ confidence belts for the logarithm of age estimated by means of this regression.

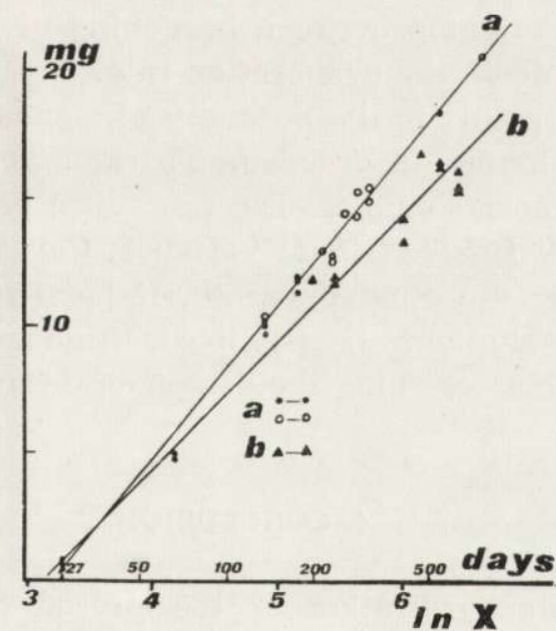

Fig. 5. Observed lens weights and linear regression of the lens weight as a function of the natural logarithm of age, for two groups of muskrats: a. wild or seminatural captivity; b. confined captivity.

Although departure from linearity is significant, the linear regression accounts for $99.4 \%$ of the lens weight variance and its predictive value is thus excellent. 
Data from the group of individuals reared in confined conditions were similarly analyzed. The fitted regression is illustrated in Fig. 5 together with that of the "natural " group. The slopes of these two lines differ significantly from each other, so lens growth is slower for the "confined " than for the "natural " group of animals. A similar difference was observed in the general growth features of these two groups of muskrats.

\subsection{Discussion}

The lens growth calibration provides a quite precise and easy method of ageing dead muskrats. When using the above presented regression, fiducial limits at the $5 \%$ probability of error level for the age, falls approximately at $11 \%$ of the estimated age. Vincent \& Quéré (1972) presented, to my knowledge, the first published reference growth curve of the lens in muskrats. Their study took place in northern France, under similar climate as my study site. But the growth curve they present, differs markedly from that illustrated in Fig. 4. This difference may be due to the fact that they used animals reared in confined conditions, and to the procedure they used to dry out the lenses (short time at $110^{\circ} \mathrm{C}$ ). Direct exposure of the lenses to a temperature of $110^{\circ} \mathrm{C}$ might provoke a hardening of their outer layer and consequently slow down the evaporation rate.

This comparison points to the necessity of standardizing the procedure for preparing the lenses, in order that a same reference growth curve be applicable for various studies. The procedure proposed in the present study yields a very small residual variance. Care must be taken to fix the eyes soon after the animal's death, if possible before a direct exposure to direct sunlight is possible. Prolonged formalin fixation hardens the lens, thus lessening the danger of decay of lens tissue during dissection.

\section{CONCLUSION}

The need for standardization of the procedures in age estimation methods, has rightly been emphasized by Pucek \& Lowe (1975), as it is a necessary condition for a calibration curve of growth to be useful. These authors also point to the necessity of knowing which level of confidence may be attached to age estimations obtained by some method. Accordingly, emphasis was placed in the present study on interval estimation and on the influence of different sources of variation, on the estimation of age. The "extrapolation " method takes into account 
the variability of growth rate between individuals. The principal constraint is that the unknown-age individual must be measured several times during its growth period. On the other hand, the lens weight method yields quite precise and low-variance age estimations; but the validity of a reference curve of lens weight, is affected by the variability in growth rate due to several (climatic, seasonal, nutritional, genetic...) factors (P ucek \& Lowe, 1975). Studies to clarify the effects of such factors are still lacking.

Acknowledgements: The present work is part of a Ph. D. thesis submitted in May 1974 at the Catholic University of Louvain, Laboratoire d'Ecologie théoretique et Biométrie. Among the persons who helped me during this project, I especially like to thank: Prof. Dr. Paul Berthet, promotor of my thesis, and Dr. Guy Gérard, for continuous assistance and discussions from which emerged the idea of the extrapolation method; the members of the Institute of Ecology of Poland, particularly Prof. Dr. Roman Andrzejewski and Dr. Krystyna Andrzejewska; Drs. E. Feytmans, J. P. Vincent, E. Fuentes, P. Meserve and R. Martin, for critical reading of the manuscript or earlier drafts of it, and my wife Paule, who assisted me through all stages of the work. While preparing my $\mathrm{Ph}$. D. thesis, I held a three year scholarship from the I.R.S.I.A. (Institut pour l'Encouragement de la Recherche Scientifique dans l'Industrie et l'Agriculture) and an eight months grant from the Polish Ministry of Culture.

\section{REFERENCES}

1. Andrzejewska K., 1971: Methods of age determination in Apodemus agrarius (P a 11 a s, 1771). Ann. Zool. Fennici, 8: 68-71.

2. Askaner T. \& Hansson L., 1967: The eye lens as an age indicator in small rodents. Oikos, $18,151-3$.

3. Dapson R. W., Otero J. C. \& Holloway W. R., 1968: Biochemical changes with age in the lenses of white mice. Nature, 218: 573.

4. Dorney R. S. \& Rush A. J. 1953. Muskrat growth and litter production. Techn. Wildl. Bull. 8: 4-32.

5. Erickson H. R. 1963: Reproduction, growth and movement of muskrats inhabiting small water areas in New-York State. N. Y. Fish \& Game J., 10: $90-117$.

6. Erringt on P. L., 1939: Observations on young muskrats in Iowa. J. Mammal., 20: $465-78$.

7. Fisher E. W. \& Perry A. E., 1970: Estimating ages of gray squirrels by lens-weights. J. Wildl. Manage, 34: $825-8$.

8. Le Boulengé E. \& Feytmans E. (in prep.).

9. Lord R. D., Jr. 1959: The lens as an indicator of age in cottontail rabbits. J. Wildl. Manage, 23: 358-60.

10. Olsen P., 1959: Muskrat breeding biology at Delta, Manitoba. J. Wildl. Manage, 23: 40-53.

11. Pucek Z. \& Lowe V. P. W., 1975: Age criteria in small mammals. [In: "Smáll mammals: their productivity and population dynamics", I.B.P. 5., Eds. F. B. Golley, K. Petrusewicz \& L. Ryszkowski] Cambridge Univ. Press: $55-72$.

12. Ruprecht A. L., 1974: Craniometric variations in central European population of Ondatra zibethica (L innaeus, 1766). Acta theriol., 19: 463-507. 
13. Sather J. E., 1954: The dentition method of ageing muskrats. Chicago Acad. Sci. Nat. Hist. Misc., 130: 1-3.

14. Snedecor G. W. \& Cochran W. G., 1969: Statistical methods. Iowa St. Univ. Press: $1-593$.

15. Vincent J. P. \& Quere J. P., 1972: Quelques données sur la reproduction et sur la dynamique de populations du Rat musqué Ondatra zibethica L. dans le nord de la France. Ann. Zool. Ecol. Anim., 4: 395-415.

16. Williams E. J., 1959: Regression analysis. J. Wiley: 1-214.

Accepted, March 23, 1977.

Eric LE BOULENGE

\section{DWIE METODY OKRESLANIA WIEKU U PIŻMAKA}

\section{Streszczenie}

Przedstawiono nową metodę określania wieku u piżmaka Ondatra zibethicus (L i nna e us, 1766), polegającą na wykorzystaniu pomiarów długości ogona i użyciu przy porównaniach wielomianu drugiego rzędu. Ponadto określano wiek na podstawie ciężaru soczewki. Stwierdzono przy tym, że tempo wzrostu soczewki u piżmaków trzymanych w niewoli jest wolniejsze niż u osobników żyjących na swobodzie. 